\title{
Fiber in Diet Is Associated with Improvement of Glycated Hemoglobin and Lipid Profile in Mexican Patients with Type 2 Diabetes
}

\author{
Lubia Velázquez-López, ${ }^{1}$ Abril Violeta Muñoz-Torres, ${ }^{2}$ Carmen García-Peña, ${ }^{3}$ \\ Mardia López-Alarcón, ${ }^{4}$ Sergio Islas-Andrade, ${ }^{5}$ and Jorge Escobedo-de la Peña ${ }^{1}$ \\ ${ }^{1}$ Unidad de Investigación en Epidemiología Clínica, Hospital "Carlos MacGregor Sánchez Navarro”, Instituto Mexicano del Seguro \\ Social, Avenida Gabriel Mancera No. 222, Colonia del Valle, Delegación Bénito Juárez, 03100 Ciudad de México, Mexico \\ ${ }^{2}$ Departamento de Salud Pública, Facultad de Medicina, Universidad Nacional Autónoma de México, 6 Piso, Edificio B, \\ Circuito Interior, Ciudad Universitaria, Avenida Universidad 3000, Ciudad de México, Mexico \\ ${ }^{3}$ Departamento de Investigación, Instituto Nacional de Geriatría, Periférico sur No. 2767, Colonia San Jerónimo Lídice, \\ Delegación Magdalena Contreras, 10200 Ciudad de México, Mexico \\ ${ }^{4}$ Unidad de Investigación Médica en Nutrición, Hospital de Pediatría, Centro Medico Nacional "Siglo XXI", Instituto Mexicano del \\ Seguro Social, Avenida Cuauhtémoc 300, Colonia Doctores, Delegación Cuauhtemoc, 06720 Ciudad de México, Mexico \\ ${ }^{5}$ Unidad de Investigación Científica de Endocrinología, Diabetes y Metabolismo, y de Enfermedades Metabólicas, \\ Centro Médico Nacional Siglo XXI, Instituto Mexicano del Seguro Social, Avenida Cuauhtémoc 300, Colonia Doctores, \\ Delegación Cuauhtemoc, 06720 Ciudad de México, Mexico
}

Correspondence should be addressed to Jorge Escobedo-de la Peña; jorgeep@unam.mx

Received 22 November 2015; Revised 26 February 2016; Accepted 21 March 2016

Academic Editor: Giovanni Annuzzi

Copyright (C) 2016 Lubia Velázquez-López et al. This is an open access article distributed under the Creative Commons Attribution License, which permits unrestricted use, distribution, and reproduction in any medium, provided the original work is properly cited.

Objective. To assess the association of dietary fiber on current everyday diet and other dietary components with glycated hemoglobin levels (HbAlc), glucose, lipids profile, and body weight body weight, in patients with type 2 diabetes. Methods. A cross-sectional survey of 395 patients with type 2 diabetes was performed. HbAlc, fasting glucose, triglycerides, and lipids profile were measured. Weight, waist circumference, blood pressure, and body composition were measured. Everyday diet with a semiquantitative food frequency questionnaire was evaluated. ANOVA, Kruskal-Wallis, chi-square tests and multivariate logistic regression were used in statistical analysis. Results. Higher fiber intake was associated with a low HbAlc, high HDL-c levels, low weight, and waist circumference. The highest tertile of calories consumption was associated with a higher fasting glucose level and weight. The highest tertile of carbohydrate consumption was associated with a lower weight. The lowest tertile of total fat and saturated fat was associated with the highest tertile of HDL-c levels, and lower saturated fat intake was associated with lower weight $(p<0.05)$. Conclusions. A higher content of fiber in the diet reduces HbAlc and triglycerides, while improving HDL-c levels. Increasing fiber consumption while lowering calorie consumption seems to be an appropriate strategy to reduce body weight and promote blood glucose control.

\section{Introduction}

Increased fiber in the diet is associated with a reduction of glycated hemoglobin (HbAlc), improved lipid profile, and loss of body weight in type 2 diabetes patients. It has been proposed that appropriate consumption of fruit in the diet may be an adequate strategy to reduce $\mathrm{HbAlc}$, given the fiber content, and prevent complications from diabetes $[1,2]$.
Several clinical trials have documented a positive effect of dietary fiber, [3] and in cross-sectional studies this effect has also been observed in different Asian populations $[1,4]$. In fact, dietary fiber can reduce the incidence of stroke in patients with type 2 diabetes [5].

There is evidence of the benefit of reduced calorie diets, though the combination of this restriction with a diet higher in protein to encourage weight loss and control glucose and 
serum lipid levels continues to generate controversy [6]. It has also been suggested that reducing the proportion of carbohydrates in the diet at the cost of increasing protein consumption improves $\mathrm{HbAlc}$ and blood pressure values as well as weight loss and this, combined with physical exercise, proffers greater protection [7]. The recommendation to include fats in the diet continues to stir up controversy regarding the effect of this on the lipids profile and body weight; strategies include reducing to $30 \%$ or less the calorie intake. Conversely, higher consumption has been suggested though with a higher content of monounsaturated and polyunsaturated fats [8].

Type 2 diabetes is one of the chronic diseases with the highest economic and social impact, as well as in the repercussions on the quality of life. In recent decades it has reached epidemic proportions; lifestyle is a very important factor in the prevention and control of the disease [9]. There is evidence of the favorable effect of adequate glycemic control to prevent micro- and macrovascular complications [10]. In the treatment regime, diet adaptation is a basic element to achieve and maintain control goals [11]. Even while diet plays a substantial role, only a minority of patients receive nutriment therapy, and an even smaller number undergo the needed changes in diet as part of their disease management [12].

Fiber consumption used to be high in the Mexican population; however, it has been reduced due to changes in eating habits [13] which undoubtedly affects habitual diet in subjects with diabetes. While there is limited information on the description of current everyday diet in patients with type 2 diabetes and its effect on major cardiovascular risk factors, the role of macronutrients on metabolic control indicators continues to foster controversy [14]. Given the foregoing, the objective of this study was to assess the association of habitual dietary fiber and other dietary components on $\mathrm{HbAlc}$, glucose, and lipid profile levels, as well as body weight, in type 2 diabetes patients in Mexico.

\section{Methods}

This report corresponds to the baseline evaluation of type 2 diabetes patients that were included in a multicenter, randomized clinical trial called Efficacy of Nutritional Therapy and Education through a Multimedia System for the Metabolic Control of Type 2 Diabetes Patients (ClinicalTrials.gov identifier: NCT02441023). Patients came from four different primary care clinics (family medical units belonging to the Mexican Social Security Institute) in Mexico City, with a previous diagnosis of diabetes, with age younger than 70 years, and with no advanced microvascular complication. An ethics and research committee approved the protocol. Patients were invited to participate at their local clinics and incorporated into the study once they had signed the letter of informed consent.

The patients included in the study underwent an extensive medical history questionnaire as well as a physical examination to evaluate the presence of severe complications. Hypertension was diagnosed when the patient stated being on antihypertensive medication or for those with values $\geq 140 / 90 \mathrm{mmHg}$ at the time of joining the study. Blood pressure was taken twice with a mercury sphygmomanometer at an interval of 4 minutes between measurement and after the patient had been seated for more than 5 minutes. The mean of the two values was used. Physical activity was considered when the patient had at least $150 \mathrm{~min} /$ week of moderateintensity aerobic physical activity, for at least 3 days/week with no more than 2 consecutive days without exercise [15].

2.1. Variables Measured. Twelve-hour-fasting blood plasma, glucose concentration, creatinine, triglycerides, total cholesterol, and fractions HDL-c values were measured; the LDL$c$ was calculated through the Friedewald equation LDL-c $=$ [total cholesterol - (triglycerides/5) - HDL-c, for triglyceride concentration < $400 \mathrm{mg} / \mathrm{dL}$ ] [16]. HbAlc was determined through the high-resolution liquid chromatography method. Excretion of urinary albumin was analyzed in the first morning urine sample through photometry/nephelometry to determine the albumin-creatinine ratio.

Standardized nutritionists who employed the Habitch method and the specifications recommended by Lohman recorded anthropometry $[17,18]$. Waist circumference was measured after determining the midpoint between the last rib and the upper edge of the iliac crest on the right side; hip circumference was measured at the widest point of the trochanters. Both of these measurements were taken on three occasions, and the mean of the second and third measurement was used for the purpose of analysis. The percentage of fat was obtained through the bioimpedance measurement of the lower segment, using a TANITA ${ }^{\mathrm{TM}}$ body composition analyzer, model TBF-215.

Diet was assessed with a food frequency questionnaire, previously validated and currently used in the Mexican National Health and Nutrition Surveys $[19,20]$. The frequency with which 116 food items and 8 types of beverages were consumed in the last year was measured. Frequency was described as never in the last year or frequency of consumption over a one-month, one-week, or one-day period in the last year. Included on the list were dairy, eggs, meat and cold cuts, fruit, vegetables, legumes and cereals, sweets, drinks, and fats to prepare or dress foodstuffs.

In order to calculate the consumption of nutrients we employed the software System to calculate nutritional vectors, developed by the National Public Health Institute of Mexico (INSP in Spanish). Dietary components analyzed were consumption of calories, proteins, carbohydrates, and lipids, as well as fiber content, cholesterol, and sodium in the diet. The consumption of nutriments was analyzed, with an adjustment of the total calories using the residual method in order to remove the effect of energy consumption of nutriments [21].

2.2. Statistical Analysis. For statistical analysis, frequency and proportion measurements were calculated, as were the mean and standard deviation to characterize the population in sociodemographic variables, disease history, and proportion of metabolic control. 
TABLE 1: Sociodemographic characteristics and comorbidity in type 2 diabetes patients.

\begin{tabular}{lc}
\hline$n=395$ & $n(\%)$ \\
\hline Age & $54.6 \pm 8.0^{*}$ \\
Sex & \\
Female & $270(68)$ \\
$\quad$ Male & $125(32)$ \\
Diagnosis of diabetes (years) & $6(3-11)^{* *}$ \\
Diabetes treatment & \\
No pharmacological treatment & $16(4)$ \\
Oral hypoglycemic agents & $300(76)$ \\
Oral hypoglycemic agents and insulin & $43(11)$ \\
Insulin & $36(9)$ \\
Lipid lowering medication & $84(21)$ \\
Follow a diet plan & $65(16)$ \\
Physical activity & $51(13)$ \\
Education in diabetes & $129(33)$ \\
Hypertension & $219(55)$ \\
Smoking & $89(22)$ \\
Alcohol consumption & $132(33)$ \\
Neuropathy & \\
Peripheral & $77(20)$ \\
Autonomic & $22(6)$ \\
Kidney disease & \\
Glomerular filtration rate $<60 \mathrm{~mL} / \mathrm{min} / 1.73 \mathrm{~m}{ }^{2}$ & $18(5)$ \\
Microalbuminuria $30-299 \mathrm{mg} / \mathrm{g}$ & $49(12)$ \\
Macroalbuminuria $>300 \mathrm{mg} / \mathrm{g}$ & $18(5)$ \\
\hline
\end{tabular}

Data are presented as frequencies and percentage. ${ }^{*}$ Age is presented as mean \pm standard deviation. ${ }^{* *}$ Years of diagnosis of diabetes are presented as median and interquartile range.

A one-factor analysis of variance was performed to identify the association between the main dietary components with metabolic control variables; the Kruskal-Wallis test was used for glucose and triglyceride variables. The chi-square test was used to identify the association between a balanced diet and the various components of metabolic control.

A logistic regression multivariate analysis was performed to identify the risk of $\mathrm{HbAlc}>7 \%$ if the dietary components were inadequate. The model was adjusted with the variables that could influence metabolic controls, such as the number of years elapsed since the time of diagnosis, the type of treatment given, and diabetes education. Data were considered statistically significant with a $p<0.05$. Statistical analysis was done using the SPSS package, version 19.

\section{Results}

The average age of the study population was $54.6 \pm 8.0$ years; oral hypoglycemic drugs were the most-used diabetes treatment (76\%); a low proportion followed a diet and physical activity (16\% and $13 \%$, resp.). Only $21 \%$ were prescribed lowering lipid medication. Of the study group, $55 \%$ had hypertension, $26 \%$ had diabetic neuropathy, $12 \%$ had microalbuminuria, and 5\% had macroalbuminuria (Table 1).
Table 2 shows the metabolic control data and the dietary characteristics of the patients. Only $34 \%$ had a desirable HbAlc; total cholesterol was within control range for over $50 \%$ of the population, whereas triglycerides, LDL-c, and HDL-c were found to be within normal range in only third of the subjects. Body mass index (BMI) was adequate in only $12 \%$; half of the population was obese and $37 \%$ of the population was overweight; over $70 \%$ of patients had an abnormal waist circumference. Diastolic blood pressure rather than systolic showed uncontrolled values (43\%). Forty-five percent consumed a diet with appropriate calorie content for their current weight, and proteins are the dietary macronutrient showing the highest degree of appropriate consumption, while $48 \%$ of the study population was found to have an appropriate fiber consumption.

Table 3 shows the association between the main dietary components and the metabolic control indicators. There is a noticeable positive association between high calorie consumption and glucose levels, while lower consumption of total and saturated fat was associated with higher levels of HDL-c. A higher intake of fiber in the diet was significantly linked to lower levels of HbAlc and triglycerides and HDL-c improvement.

The association between the components of the diet and the anthropometric indicators is presented in Table 4. A greater consumption of calories in the diet was associated with greater weight, whereas a higher consumption of total carbohydrates produced a reverse association with weight gain. Lower consumption of saturated fat is associated with less weight, whereas a higher fiber intake is associated with lower levels of weight and waist circumference.

In the multivariate analysis (Table 5), a lower intake of dietary fiber (first quartile) was independently associated with poor glycemic control, together with longer duration of the disease and lack of education in diabetes. In a similar model, the lowest tertile of fiber consumption increased the risk of inadequately low HDL-c levels, as did the higher the body weight, but the effects of duration of diabetes and education in diabetes were lost (Table 6).

\section{Discussion}

In patients with type 2 diabetes, adherence to an appropriate meal plan and physical activity are important components in controlling the disease. Of the population assessed, only $16 \%$ of patients followed a diet as part of their treatment and only 13\% exercised. As for metabolic control, only 3 out of 10 patients had HbAlc $<7 \%$, a proportion similar to what is reported in the National Health Survey of Mexico 2012, in which only a small group adheres to diet and exercise regimes as part of treatment, and only $24 \%$ have an adequate glycemic control [22].

Regarding the characteristics of the diet, only 2 out of 10 patients have adequate consumption of whole simple carbohydrates, only $16 \%$ consume adequate proportions of fat, and only $8 \%$ have a proper balance in their daily diet, even though 4 out of 10 patients are consuming a diet conducive to attaining healthful body weight $(1,200$ to 1,600 
TABLE 2: Metabolic control and diet characteristics of the studied population $(n=395)$.

\begin{tabular}{|c|c|c|c|}
\hline & $\begin{array}{c}\text { Mean } \pm \text { SD or median (Interquartile } \\
\text { range) }\end{array}$ & Reference value & $\begin{array}{c}\text { Adequate control } \\
n(\%)\end{array}$ \\
\hline \multicolumn{4}{|l|}{ Biochemical variables } \\
\hline $\operatorname{HbAlc}(\%)$ & $8.48 \pm 2.2$ & $<7 \%$ & $136(34)$ \\
\hline Fasting glucose (mg/dL) & $146(117-201)$ & $70-130 \mathrm{mg} / \mathrm{dL}$ & $149(38)$ \\
\hline Total cholesterol (mg/dL) & $195.90 \pm 41.1$ & $<200 \mathrm{mg} / \mathrm{dL}$ & $229(58)$ \\
\hline LDL-c (mg/dL) & $112.46 \pm 32.0$ & $<100 \mathrm{mg} / \mathrm{dL}$ & $128(32)$ \\
\hline HDL-c (mg/dL) & $41.68 \pm 11.2$ & $>50 \mathrm{~F}$ and $>40 \mathrm{M} \mathrm{mg} / \mathrm{dL}$ & $70(25.9) / 41(33)$ \\
\hline Triglycerides (mg/dL) & $180(134-251)$ & $<150 \mathrm{mg} / \mathrm{dL}$ & $134(34)$ \\
\hline Creatinine $(\mathrm{mg} / \mathrm{dL})$ & $0.81 \pm 0.2$ & $0.7-1.3 \mathrm{mg} / \mathrm{dL}$ & $387(98)$ \\
\hline \multicolumn{4}{|c|}{ Anthropometric variables and blood pressure (BP) } \\
\hline Weight $(\mathrm{kg})$ & $75.42 \pm 14.8$ & - & - \\
\hline Body mass index $\left(\mathrm{kg} / \mathrm{m}^{2}\right)$ & $30.52 \pm 5.3$ & $18.5-24.9 \mathrm{kgm}^{2}$ & $47(12)$ \\
\hline Waist circumference $(\mathrm{cm})$ & $100.48 \pm 12.4$ & $<80(\mathrm{~F})$ and $<90(\mathrm{M}) \mathrm{cm}$ & $12(4) / 24(19)$ \\
\hline Body fat (\%) & $41.90 \pm 11.7$ & $20-30(\mathrm{~F})$ and $12-20(\mathrm{M}) \mathrm{cm}$ & $5(4) / 12(4)$ \\
\hline Systolic BP (mmHg) & $124.50 \pm 15.9$ & $\leq 130 \mathrm{mmHg}$ & $324(83)$ \\
\hline Diastolic BP (mmHg) & $83.25 \pm 11.1$ & $\leq 80 \mathrm{mmHg}$ & $224(57)$ \\
\hline \multicolumn{4}{|l|}{ Diet variables } \\
\hline Total energy kcal/day ${ }^{1}$ & $1792.25 \pm 683.2$ & $20-30 \mathrm{kcal} / \mathrm{kg} / \mathrm{day}$ & $179(45)$ \\
\hline Carbohydrates (g/day)/\% & $225.65 \pm 93.6 / 50.3 \pm 7.8$ & $50-55 \%$ & $97(25)$ \\
\hline Soluble CHO g/day & $59.00(37.87-70.81) / \mathbf{1 3 . 1} \pm \mathbf{4 . 5}$ & $<10 \%$ & $97(25)$ \\
\hline Proteins g/day/\% & $67.59 \pm 23.3 / \mathbf{1 5 . 5} \pm \mathbf{3 . 0}$ & $10-15 \%$ & $188(48)$ \\
\hline Fats g/day/\% & $70.02 \pm 28.8 / 36.0 \pm 7.0$ & $25-30 \%$ & $64(16)$ \\
\hline Dietary fiber $\mathrm{g} / 1000 \mathrm{kcal}$ & $13.83 \pm 0.4$ & $14 \mathrm{~g} / 1000 \mathrm{Kcal}$ & $188(48)$ \\
\hline Saturated fats g/day/\% & $20.24 \pm 9.4 / 10.1 \pm 2.2$ & $<7 \%$ & $28(7)$ \\
\hline Fructose g/day & $20(14-27)$ & $(20 \mathrm{~g}) /$ day & $195(49)$ \\
\hline Cholesterol mg/day & $195(129-252)$ & $<200 \mathrm{mg}$ & $212(54)$ \\
\hline Sodium mg/day & $1492.57 \pm 594.0$ & $<2000 \mathrm{mg}$ & $269(82)$ \\
\hline Balanced diet ${ }^{2}$ & - & - & $30(8)$ \\
\hline
\end{tabular}

${ }^{1}$ Caloric recommendations for adults older than 51 years and sedentary behavior were considered, as well as a caloric reduction for subjects with diabetes, obesity, or overweight; in normal weight, $30 \mathrm{kcal} / \mathrm{kg} / \mathrm{day}$ was considered in reference value, in overweight, $25 \mathrm{kcal} / \mathrm{kg} / \mathrm{day}$, and, in obesity, $20 \mathrm{kcal} / \mathrm{kg} / \mathrm{day}$. ${ }^{2}$ Balanced diet was considered when the proportion of carbohydrates was between 50 and $55 \%$, proteins $10-15 \%$, and fats $<30 \%$ from total kcal value. $\mathrm{F}$ : female. M: male.

calories), calories suggested if the individual is sedentary, with overweight or obesity, and more than 50 years old. Other authors have proven the association between obesity and a diet high in calories, saturated fat, sodium, and a lower content of fiber in type 2 diabetes patients [23]. The results shown are consistent with the association between higher calorie consumption and greater glycemic and weight instability. A very small proportion of patients exhibit a proper balance in diet; thus it is necessary to encourage them to adhere to a more healthful alimentary regime.

An increased consumption of carbohydrates was linked significantly to lower weight. No differences were found regarding the consumption of carbohydrates and glucose or HbAlc levels, similar to what has been observed by other authors when comparing the effect of prescribing diets with a greater or lesser carbohydrate content, on HbAlc levels and body weight [24]. However, a review of clinical trials where patients were followed up for more than six months confirms the benefit of prescribing reduced carbohydrate diets, of low glycemic index, Mediterranean diets, and diets with higher protein content to improve cardiovascular risk markers in patients with type 2 diabetes [25]. The jury is still out for a real consensus regarding the distribution of macronutriments in the diet of the diabetic patient. In fact, consensus reached on the treatment of the disease suggests that diet should be tailored and adjusted to the comorbidity of each patient [11]. The effect that the amount of carbohydrates in the diet has on body weight and glycemic levels merits further evaluation and monitoring. It is well known that one of the main health problems linked to diabetes is obesity, reported to be as high 
TABLE 3: Association of diet components and metabolic control variables $(n=395)$.

\begin{tabular}{|c|c|c|c|c|c|}
\hline Tertiles & $\begin{array}{c}\text { HbAlc } \\
\%\end{array}$ & $\begin{array}{l}\text { Glucose } \\
\mathrm{mg} / \mathrm{dL}\end{array}$ & $\begin{array}{l}\text { Triglycerides } \\
\text { mg/dL }\end{array}$ & $\begin{array}{l}\text { HDL-c } \\
\mathrm{mg} / \mathrm{dL}\end{array}$ & $\begin{array}{l}\text { LDL-c } \\
\mathrm{mg} / \mathrm{dL}\end{array}$ \\
\hline \multicolumn{6}{|l|}{ Calories (kcal) } \\
\hline $812-1440$ & $8.40 \pm 2.1$ & $140.0(116.2,189.7)$ & $181.0(131.0,252.0)$ & $41.8 \pm 10.6$ & $113.9 \pm 31.2$ \\
\hline $1441-1922$ & $8.35 \pm 2.3$ & $141.0(112.2,193.5)$ & $171.5(135.2,235.0)$ & $41.1 \pm 9.7$ & $111.7 \pm 31.5$ \\
\hline $1922-3420$ & $8.70 \pm 2.3$ & $157.0(123.0,224.0)$ & $182.0(135.0,267.0)$ & $42.2 \pm 13.1$ & $111.6 \pm 33.2$ \\
\hline$p$ value & 0.400 & 0.0130 & 0.603 & 0.719 & 0.811 \\
\hline \multicolumn{6}{|c|}{ Carbohydrates (g/day) } \\
\hline $116.45-211.36$ & $8.6 \pm 2.1$ & $141.0(116.5,215.5)$ & $186.0(141.5,251.5)$ & $40.6 \pm 10.0$ & $108.0 \pm 32.0$ \\
\hline $211.37-238.80$ & $8.4 \pm 2.3$ & $145.0(113.0,200.0)$ & $174.0(130.5,243.0)$ & $41.4 \pm 13.4$ & $116.1 \pm 33.2$ \\
\hline $238.81-298.50$ & $8.4 \pm 2.3$ & $148.5(119.0,189.7)$ & $168.5(128.2,247.0)$ & $43.1 \pm 10.1$ & $112.5 \pm 29.2$ \\
\hline$p$ value & 0.767 & 0.882 & 0.254 & 0.202 & 0.117 \\
\hline \multicolumn{6}{|l|}{ Proteins (g/day) } \\
\hline $40.72-63.06$ & $8.5 \pm 2.3$ & $152.0(121.5,198.0)$ & $168.0(131.0,255.5)$ & $42.1 \pm 9.7$ & $117.9 \pm 30.11$ \\
\hline $63.07-70.36$ & $8.7 \pm 2.4$ & $151.0(114.0,211.5)$ & $189.0(138.7,242.5)$ & $42.0 \pm 12.9$ & $110.3 \pm 31.8$ \\
\hline $70.37-98.24$ & $8.2 \pm 2.0$ & $139.0(113.0,199.0)$ & $179.0(136.0,252.0)$ & $41.2 \pm 11.05$ & $110.21 \pm 33.3$ \\
\hline$p$ value & 0.166 & 0.196 & 0.418 & 0.776 & 0.080 \\
\hline \multicolumn{6}{|l|}{ Fats (g/day) } \\
\hline $12.92-64.50$ & $8.5 \pm 2.3$ & $148.0(119.0,195.0)$ & $174.0(130.0,257.0)$ & $43.9 \pm 13.3$ & $112.3 \pm 29.0$ \\
\hline $64.51-74.77$ & $8.5 \pm 2.3$ & $152.0(119.0,203.0)$ & $179.0(137.0,266.5)$ & $40.1 \pm 10.1$ & $114.4 \pm 34.7$ \\
\hline $74.78-149.02$ & $8.4 \pm 2.1$ & $140.0(111.0,216.0)$ & $182.0(141.0,235.0)$ & $41.6 \pm 9.7$ & $110.6 \pm 31.1$ \\
\hline$p$ value & 0.859 & 0.627 & 0.779 & 0.017 & 0.633 \\
\hline \multicolumn{6}{|c|}{ Saturated fats (g/day) } \\
\hline $1.18-18.20$ & $8.3 \pm 2.1$ & $146.0(115.0,194.0)$ & $165.0(125.0,236.0)$ & $43.9 \pm 9.9$ & $116.8 \pm 28.2$ \\
\hline $18.21-21.89$ & $8.7 \pm 2.4$ & $145.0(119.0,205.0)$ & $184.0(141.0,270.0)$ & $40.0 \pm 9.8$ & $112.9 \pm 34.6$ \\
\hline $21.90-54.28$ & $8.5 \pm 2.2$ & $149.0(116.0,209.0)$ & $183.0(138.0,238.0)$ & $41.1 \pm 13.4$ & $107.6 \pm 31.7$ \\
\hline$p$ value & 0.260 & 0.968 & 0.096 & 0.015 & 0.065 \\
\hline \multicolumn{6}{|c|}{ Dietary fiber (g/day) } \\
\hline $4.63-21.65$ & $8.6 \pm 2.3$ & $151.5(119.5,208.5)$ & $183.0(142.8,251.8)$ & $42.0 \pm 12.8$ & $114.5 \pm 31.5$ \\
\hline $21.66-26.68$ & $8.8 \pm 2.3$ & $152.0(116.0,221.0)$ & $186.0(133.0,284.0)$ & $39.5 \pm 9.0$ & $111.0 \pm 33.7$ \\
\hline $26.69-78.38$ & $8.0 \pm 2.1$ & $136.5(114.0,186.8)$ & $163.0(123.5,221.0)$ & $43.5 \pm 11.2$ & $111.8 \pm 30.5$ \\
\hline$p$ value & 0.011 & 0.203 & 0.007 & 0.016 & 0.622 \\
\hline
\end{tabular}

Data are presented as mean \pm standard deviation or median (interquartile range), according to each tertile of diet components. Comparison was performed with ANOVA (means) or Kruskal-Wallis (medians).

as $50 \%$ in this population, and obesity elevates the risk of macrovascular disease. The habitual diet of patients is one of the most important factors to reduce obesity. It is imperative to design educational strategies geared toward improving adherence to a healthful diet.

In this study, consumption of proteins was not associated with improved glycemic control. Other authors have reported the benefits of higher protein content in the diet for an improvement of HbAlc and body weight, as well as some cardiovascular risk indicators [26]. Different theories regarding the effect of a high protein diet have been described, including the benefit of producing greater satiety and reducing consumption of carbohydrates - which provide less energyleading to weight loss. On the other hand, the higher thermal effect of proteins versus carbohydrates fosters greater weight loss and improved metabolic control in overweight or obese patients [27].

As for fat in the diet, high consumption of saturated fat is linked to higher risk of cardiovascular disease, obesity, and dyslipidemia when compared to a higher consumption of polyunsaturated fat. In our results, increased consumption of saturated fat was linked to lower levels of HDL-c and higher body weight. These results are consistent with the broadly described benefits of the Mediterranean diet, in which the quality of fat in the diet is what leads to a reduction of cardiovascular risk indicators. Results encourage higher consumption of poly- and monounsaturated fat and a reduction of at least $10 \%$ of saturated fat in the total calorie intake [28]. 
TABLE 4: Association of diet components with anthropometric and body composition variables.

\begin{tabular}{|c|c|c|c|c|}
\hline Tertiles & Weight $(\mathrm{kg})$ & Waist circumference $(\mathrm{cm})$ & Body mass index $\left(\mathrm{kg} / \mathrm{m}^{2}\right)$ & Body fat (\%) \\
\hline \multicolumn{5}{|l|}{ Calories (kcal) } \\
\hline 812-1440 & $72.6 \pm 13.6$ & $99.4 \pm 12.2$ & $29.8 \pm 5.0$ & $42.4 \pm 11.1$ \\
\hline $1441-1922$ & $76.4 \pm 16.0$ & $100.9 \pm 12.6$ & $31.0 \pm 5.5$ & $41.9 \pm 11.3$ \\
\hline $1922-3420$ & $77.3 \pm 14.6$ & $101.2 \pm 12.6$ & $30.8 \pm 5.3$ & $41.4 \pm 12.9$ \\
\hline$p$ value & 0.022 & 0.458 & 0.145 & 0.782 \\
\hline \multicolumn{5}{|c|}{ Carbohydrates (g/day) } \\
\hline $116.45-211.36$ & $78.1 \pm 16.0$ & $101.4 \pm 12.5$ & $30.8 \pm 5.3$ & $41.2 \pm 11.3$ \\
\hline $211.37-238.80$ & $74.2 \pm 14.5$ & $100.6 \pm 12.4$ & $30.4 \pm 5.3$ & $42.7 \pm 12.3$ \\
\hline 238.81-298.50 & $73.8 \pm 13.6$ & $99.4 \pm 12.4$ & $30.2 \pm 5.3$ & $41.7 \pm 11.7$ \\
\hline$p$ value & 0.035 & 0.416 & 0.654 & 0.572 \\
\hline \multicolumn{5}{|l|}{ Proteins (g/day) } \\
\hline $40.72-63.06$ & $75.9 \pm 14.1$ & $101.5 \pm 12.2$ & $30.9 \pm 5.4$ & $43.2 \pm 11.9$ \\
\hline $63.07-70.36$ & $74.5 \pm 15.1$ & $99.8 \pm 12.4$ & $30.2 \pm 4.9$ & $41.9 \pm 11.1$ \\
\hline $70.37-98.24$ & $75.8 \pm 15.4$ & $100.2 \pm 12.6$ & $30.4 \pm 5.6$ & $40.5 \pm 12.2$ \\
\hline$p$ value & 0.705 & 0.528 & 0.538 & 0.172 \\
\hline \multicolumn{5}{|l|}{ Fats (g/day) } \\
\hline $12.92-64.50$ & $75.0 \pm 14.5$ & $101.0 \pm 12.4$ & $30.5 \pm 5.4$ & $40.9 \pm 12.1$ \\
\hline $64.51-74.77$ & $74.3 \pm 14.1$ & $99.7 \pm 12.3$ & $30.3 \pm 5.2$ & $42.6 \pm 11.7$ \\
\hline $74.78-149.02$ & $76.9 \pm 15.9$ & $100.7 \pm 12.5$ & $30.7 \pm 5.3$ & $42.1 \pm 11.5$ \\
\hline$p$ value & 0.347 & 0.698 & 0.853 & 0.462 \\
\hline \multicolumn{5}{|c|}{ Saturated fats (g/day) } \\
\hline $1.18-18.20$ & $72.6 \pm 13.5$ & $99.2 \pm 12.8$ & $29.8 \pm 5.2$ & $40.9 \pm 12.2$ \\
\hline $18.21-21.89$ & $75.9 \pm 15.4$ & $100.4 \pm 11.8$ & $30.7 \pm 5.3$ & $42.7 \pm 11.0$ \\
\hline $21.90-54.28$ & $77.7 \pm 15.3$ & $101.8 \pm 12.6$ & $31.0 \pm 5.3$ & $42.0 \pm 12.0$ \\
\hline$p$ value & 0.020 & 0.223 & 0.183 & 0.450 \\
\hline \multicolumn{5}{|c|}{ Dietary fiber (g/day) } \\
\hline $4.63-21.65$ & $78.1 \pm 14.2$ & $102.5 \pm 12.2$ & $31.0 \pm 5.2$ & $42.2 \pm 12.5$ \\
\hline $21.66-26.68$ & $74.1 \pm 14.9$ & $99.3 \pm 11.5$ & $30.1 \pm 5.0$ & $41.9 \pm 10.9$ \\
\hline $26.69-78.38$ & $73.9 \pm 15.2$ & $99.5 \pm 13.3$ & $30.4 \pm 5.6$ & $41.5 \pm 11.9$ \\
\hline$p$ value & 0.037 & 0.063 & 0.407 & 0.888 \\
\hline
\end{tabular}

Data are presented as mean \pm standard deviation, according to each tertile of diet components. Comparison was performed with ANOVA.

The association between dietary fiber consumption and improved HbAlc, HDL-c, and weight levels is consistent with what has been reported by other authors regarding the effect of fiber in reducing postprandial glucose, increased satiety, better glycemic control, improvement of cardiovascular risk factors, and reduced risk of macrovascular complications $[29,30]$. Even though, in the studied population, $48 \%$ had an adequate dietetic fiber consumption (14 g/1000 calories), it is still important to promote a varied diet, with a high consumption of high soluble and insoluble fiber foods, mainly derived from vegetables, whole grains, dried fruits, and fruits with a low glycemic index.

An important component for controlling the diabetes is the education; only three out of every ten patients assessed have been in an education program. Our results show the protective effect that this strategy provides to aid the attainment of improved HbAlc levels, added to what has been reported regarding the prevention of micro- and macrovascular complications [31]. Despite the foregoing, education continues to be an underused approach; we must insist on its use as a measure to promote a healthful lifestyle and a better care of the disease. Comprehensive treatment should be aimed at obtaining adequate metabolic control and at encouraging the detection and timely medical and nutritional treatment of diabetes [32].

\section{Conclusions}

A higher content of fiber in the diet had an impact on reducing $\mathrm{HbAlc}$ and triglycerides, while improving HDL-c levels. Lower calorie and saturated fat consumption may still be an appropriate strategy to reduce body weight, promote blood glucose control, and improve HDL-c levels. Since metabolic control is deficient in Mexicans, we must insist on a higher fiber content in the diet, given the beneficial 
TABLE 5: Odds ratios (OR) and $95 \%$ confidence intervals $\left(\mathrm{CI}_{95 \%}\right)$ derived from a multivariate logistic regression model to identify the risk of an inadequate glycemic control (HbAlc > 7\%).

\begin{tabular}{|c|c|c|c|}
\hline & OR & $\mathrm{CI}_{95 \%}$ & $p$ value \\
\hline \multicolumn{4}{|l|}{ Total energy (kcal) } \\
\hline $812-1440$ & 1 & & \\
\hline $1441-1922$ & 0.81 & $0.46-1.41$ & 0.459 \\
\hline $1922-3420$ & 1.35 & $0.75-2.41$ & 0.309 \\
\hline \multicolumn{4}{|l|}{ Dietary fiber (g/day) } \\
\hline $26.69-78.38$ & 1 & & \\
\hline $21.66-26.68$ & 2.16 & $1.22-3.83$ & 0.008 \\
\hline $4.63-21.65$ & 1.91 & $1.08-3.35$ & 0.024 \\
\hline \multicolumn{4}{|l|}{ Years since diagnosis } \\
\hline$<5$ years (reference) & 1 & & \\
\hline $5-10$ years & 2.26 & $1.28-3.99$ & 0.005 \\
\hline$>10$ years & 2.01 & $1.01-3.78$ & 0.029 \\
\hline \multicolumn{4}{|l|}{ Pharmacologic treatment } \\
\hline Oral hypoglycemic drugs (reference) & 1 & & \\
\hline Oral hypoglycemic drugs and insulin & 6.97 & $2.32-20.86$ & 0.001 \\
\hline Insulin & 5.28 & $1.70-16.35$ & 0.004 \\
\hline No drugs & 0.79 & $0.27-2.36$ & 0.683 \\
\hline \multicolumn{4}{|l|}{ Education in diabetes } \\
\hline Yes (reference) & 1 & & \\
\hline No & 2.19 & $1.35-3.42$ & 0.002 \\
\hline \multicolumn{4}{|l|}{ Sex } \\
\hline Male (reference) & 1 & & \\
\hline Female & 0.84 & $0.51-1.38$ & 0.496 \\
\hline \multicolumn{4}{|l|}{ BMI } \\
\hline Normal weight & 1 & & \\
\hline Overweight & 1.05 & $0.49-2.25$ & 0.890 \\
\hline Obesity & 1.02 & $0.48-2.16$ & 0.950 \\
\hline
\end{tabular}

Inadequate glycemic control (HbAlc > 7\%), odds ratios (OR), and $95 \%$ confidence intervals $\left(\mathrm{CI}_{95 \%}\right)$. Calories and dietary fiber are presented in tertiles. BMI: body mass index. Individuals were considered of normal weight with BMI $<24.9$, overweight with $25-29.9$, and obesity $>30 \mathrm{~kg} / \mathrm{m}^{2}$.

effects noted in bringing down HbAlc levels and weight, while improving lipid profile.

\section{Ethical Approval}

This study was conducted according to the guidelines laid down in the Declaration of Helsinki and all procedures involving human subjects/patients were approved by the Ethics and Health Research Committee of the Mexican Social Security Institute.

\section{Consent}

Written informed consent was obtained from all subjects/patients.

\section{Competing Interests}

The authors declare that they have no competing interests.
TABLE 6: Odds ratios (OR) and 95\% confidence intervals $\left(\mathrm{CI}_{95 \%}\right)$ derived from a multivariate logistic regression model to identify the risk of an inadequate HDL-c.

\begin{tabular}{|c|c|c|c|}
\hline & OR & $\mathrm{CI}_{95 \%}$ & $p$ value \\
\hline \multicolumn{4}{|l|}{ Total energy (kcal) } \\
\hline $812-1440$ & 1 & & \\
\hline $1441-1922$ & 1.029 & $0.56-1.83$ & 0.977 \\
\hline $1922-3420$ & 0.87 & $0.47-1.58$ & 0.640 \\
\hline \multicolumn{4}{|l|}{ Dietary fiber (g/day) } \\
\hline 26.69-78.38 & 1 & & \\
\hline $21.66-26.68$ & 1.05 & $0.57-1.94$ & 0.873 \\
\hline $4.63-21.65$ & 1.79 & $0.98-3.27$ & 0.059 \\
\hline \multicolumn{4}{|l|}{ Years since diagnosis } \\
\hline$<5$ years (reference) & 1 & & \\
\hline $5-10$ years & 1.46 & $0.80-2.62$ & 0.211 \\
\hline$>10$ years & 1.13 & $0.60-2.12$ & 0.701 \\
\hline \multicolumn{4}{|l|}{ Pharmacologic treatment } \\
\hline Oral hypoglycemic drugs (reference) & 1 & & \\
\hline Oral hypoglycemic drugs and insulin & 1.01 & $0.45-2.24$ & 0.930 \\
\hline Insulin & 0.65 & $0.29-1.46$ & 0.300 \\
\hline No drugs & 1.83 & $0.48-6.90$ & 0.369 \\
\hline \multicolumn{4}{|l|}{ Education in diabetes } \\
\hline Yes (reference) & 1 & & \\
\hline No & 1.45 & $0.89-2.37$ & 0.133 \\
\hline \multicolumn{4}{|l|}{ Sex } \\
\hline Male (reference) & 1 & & \\
\hline Female & 1.55 & $0.92-2.61$ & 0.103 \\
\hline Fats (g/day) & 1.018 & $1.00-1.03$ & 0.046 \\
\hline $12.92-64.50$ & 1 & & \\
\hline $64.51-74.77$ & 1.87 & $1.02-3.39$ & 0.040 \\
\hline $74.78-149.02$ & 1.19 & $0.65-2.17$ & 0.573 \\
\hline \multicolumn{4}{|l|}{ Saturated fats (g/day) } \\
\hline $1.18-18.20$ & 1 & & \\
\hline $18.21-21.89$ & 1.32 & $0.72-2.43$ & 0.366 \\
\hline $21.90-54.28$ & 1.20 & $0.61-2.35$ & 0.590 \\
\hline \multicolumn{4}{|l|}{ Physical activity } \\
\hline Yes & 1 & & \\
\hline No & 1.20 & $0.61-2.35$ & 0.590 \\
\hline Peso Kg & 1.017 & $1.00-1.03$ & 0.042 \\
\hline
\end{tabular}

\section{Acknowledgments}

This study was supported by a research grant from the Mexico National Science and Technology Council (Consejo Nacional de Ciencia y Tecnología, CONACYT) no. SALUD-2012-01181015.

\section{References}

[1] L. Yang, L. Shu, J. Jiang et al., "Long-term effect of dietary fibre intake on glycosylated haemoglobin Alc level and glycaemic 
control status among Chinese patients with type 2 diabetes mellitus," Public Health Nutrition, vol. 17, no. 8, pp. 1858-1856, 2014.

[2] S. Tanaka, Y. Yoshimura, R. Kawasaki et al., "Fruit intake and incident diabetic retinopathy with type 2 diabetes," Epidemiology, vol. 24, no. 2, pp. 204-211, 2013.

[3] R. E. Post, A. G. Mainous III, D. E. King, and K. N. Simpson, "Dietary fiber for the treatment of type 2 diabetes mellitus: a meta-analysis," Journal of the American Board of Family Medicine, vol. 25, no. 1, pp. 16-23, 2012.

[4] H. Fujii, M. Iwase, T. Ohkuma et al., "Impact of dietary fiber intake on glycemic control, cardiovascular risk factors and chronic kidney disease in Japanese patients with type 2 diabetes mellitus: the Fukuoka Diabetes Registry," Nutrition Journal, vol. 12, article 159, 2013.

[5] S. Tanaka, Y. Yoshimura, C. Kamada et al., "Intakes of dietary fiber, vegetables, and fruits and incidence of cardiovascular disease in Japanese patientswith type 2 diabetes," Diabetes Care, vol. 36, no. 12, pp. 3916-3922, 2013.

[6] T. P. Wycherley, L. J. Moran, P. M. Clifton, M. Noakes, and G. D. Brinkworth, "Effects of energy-restricted high-protein, low-fat compared with standard-protein, low-fat diets: a metaanalysis of randomized controlled trials," The American Journal of Clinical Nutrition, vol. 96, no. 6, pp. 1281-1298, 2012.

[7] T. P. Wycherley, M. Noakes, P. M. Clifton, X. Cleanthous, J. B. Keogh, and G. D. Brinkworth, "A high-protein diet with resistance exercise training improves weight loss and body composition in overweight and obese patients with type 2 diabetes," Diabetes Care, vol. 33, no. 5, pp. 969-976, 2010.

[8] L. Schwingshackl and G. Hoffmann, "Comparison of effects of long-term low-fat vs high-fat diets on blood lipid levels in overweight or obese patients: a systematic review and metaanalysis," Journal of the Academy of Nutrition and Dietetics, vol. 113, no. 12, pp. 1640-1661, 2013.

[9] M. A. Ariza, V. G. Vimalananda, and J. L. Rosenzweig, "The economic consequences of diabetes and cardiovascular disease in the United States," Reviews in Endocrine and Metabolic Disorders, vol. 11, no. 1, pp. 1-10, 2010.

[10] M. Monami, J. E. Adalsteinsson, C. M. Desideri, B. Ragghianti, I. Dicembrini, and E. Mannucci, "Fasting and post-prandial glucose and diabetic complication. A meta-analysis," Nutrition, Metabolism and Cardiovascular Diseases, vol. 23, no. 7, pp. 591598, 2013.

[11] P. A. Dyson, T. Kelly, T. Deakin et al., "Diabetes UK evidencebased nutrition guidelines for the prevention and management of diabetes," Diabetic Medicine, vol. 28, no. 11, pp. 1282-1288, 2011.

[12] G. Nthangeni, N. P. Steyn, M. Alberts et al., "Dietary intake and barriers to dietary compliance in black type 2 diabetic patients attending primary health-care services," Public Health Nutrition, vol. 5, no. 2, pp. 329-338, 2002.

[13] J. K. Montez and K. Eschbach, "Country of birth and language are uniquely associated with intakes of fat, fiber, and fruits and vegetables among Mexican-American women in the United States," Journal of the American Dietetic Association, vol. 108, no. 3, pp. 473-480, 2008.

[14] A. B. Evert, J. L. Boucher, M. Cypress et al., "Nutrition therapy recommendations for the management of adults with diabetes," Diabetes Care, vol. 37, supplement 1, pp. S120-S143, 2014.
[15] American Diabetes Association, "Foundations of care: education, nutrition, physical activity, smoking cessation, psychosocial care, andimmunization," Diabetes Care, vol. 38, supplement 1, pp. S20-S30, 2015.

[16] W. T. Friedewald, R. I. Levy, and D. S. Fredrickson, "Estimation of the concentration of low density lipoprotein cholesterol in plasma, without use of the preparative ultracentrifuge," Clinical Chemistry, vol. 18, no. 6, pp. 499-502, 1972.

[17] J. P. Habicht, "Standardization of quantitative epidemiological methods in the field," Boletin de la Oficina Sanitaria Panamericana, vol. 76, no. 5, pp. 375-384, 1974.

[18] T. Lohman, R. Martorell, and A. F. Roche, Anthropometric Standardization Reference Manual, Human Kinetics Books, Champaign, Ill, USA, 1988.

[19] M. Hernández-Avila, I. Romieu, S. Parra, J. Hernández-Avila, H. Madrigal, and W. Willett, "Validity and reproducibility of a food frequency questionnaire to assess dietary intake of women living in Mexico City," Salud Publica de Mexico, vol. 40, no. 2, pp. 133-140, 1998.

[20] S. Rodríguez-Ramírez, V. Mundo-Rosas, A. Jiménez-Aguilar, and T. Shamah-Levy, "Methodology for the analysis of dietary data from the mexican national health and nutrition survey 2006," Salud Publica de Mexico, vol. 51, supplement 4, pp. S523S529, 2009.

[21] W. Willett and M. J. Stampfer, “Total energy intake: implications for epidemiologic analyses," American Journal of Epidemiology, vol. 124, no. 1, pp. 17-27, 1986.

[22] M. Hernández-Ávila, J. P. Gutiérrez, and N. Reynoso-Noverón, "Diabetes mellitus in Mexico. Status of the epidemic," Salud Pública de México, vol. 55, supplement 2, pp. S129-S136, 2013.

[23] S. Jarvandi, R. Gougeon, A. Bader, and K. Dasgupta, "Differences in food intake among obese and nonobese women and men with type 2 diabetes," Journal of the American College of Nutrition, vol. 30, no. 4, pp. 225-232, 2011.

[24] S. Y. Nowlin, M. J. Hammer, and G. D’Eramo Melkus, "Diet, inflammation, and glycemic control in type 2 diabetes: an integrative review of the literature," Journal of Nutrition and Metabolism, vol. 2012, Article ID 542698, 21 pages, 2012.

[25] O. Ajala, P. English, and J. Pinkney, "Systematic review and meta-analysis of different dietary approaches to the management of type 2 diabetes," American Journal of Clinical Nutrition, vol. 97, no. 3, pp. 505-516, 2013.

[26] H. H. Mehrabani, S. Salehpour, Z. Amiri, S. J. Farahani, B. J. Meyer, and F. Tahbaz, "Beneficial effects of a high-protein, lowglycemic-load hypocaloric diet in overweight and obese women with polycystic ovary syndrome: a randomized controlled intervention study," Journal of the American College of Nutrition, vol. 31, no. 2, pp. 117-125, 2012.

[27] P. M. Clifton, K. Bastiaans, and J. B. Keogh, "High protein diets decrease total and abdominal fat and improve CVD risk profile in overweight and obese men and women with elevated triacylglycerol," Nutrition, Metabolism and Cardiovascular Diseases, vol. 19, no. 8, pp. 548-554, 2009.

[28] M. Kratz, T. Baars, and S. Guyenet, "The relationship between high-fat dairy consumption and obesity, cardiovascular, and metabolic disease," European Journal of Nutrition, vol. 52, no. 1, pp. 1-24, 2013.

[29] J. Jiang, H. Qiu, G. Zhao et al., "Dietary fiber intake is associated with hbalc level among prevalent patients with type 2 diabetes in pudong new area of Shanghai, China," PLoS ONE, vol. 7, no. 10, Article ID e46552, 2012. 
[30] Z. Tan, X. Ruan, Y. Chen et al., "Heterogeneous associations of insoluble dietary fiber intake with subsequent glycosylated $\mathrm{Hb}$ levels among Chinese adults with type 2 diabetes: a quantile regression approach," British Journal of Nutrition, vol. 28, pp. 958-963, 2014.

[31] C. Yuan, C. W. K. Lai, L. W. C. Chan, M. Chow, H. K. W. Law, and M. Ying, "The effect of diabetes self-management education on body weight, glycemic control, and other metabolic markers in patients with type 2 diabetes mellitus," Journal of Diabetes Research, vol. 2014, Article ID 789761, 6 pages, 2014.

[32] S. G. Coca, F. Ismail-Beigi, N. Haq, H. M. Krumholz, and C. R. Parikh, "Role of intensive glucose control in development of renal end points in type 2 diabetes mellitus: systematic review and meta-analysis," Archives of Internal Medicine, vol. 172, no. 10, pp. 761-769, 2012. 


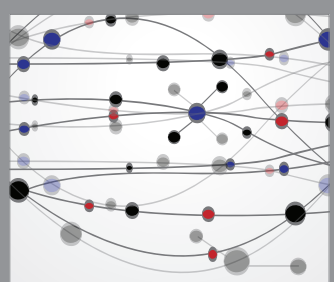

The Scientific World Journal
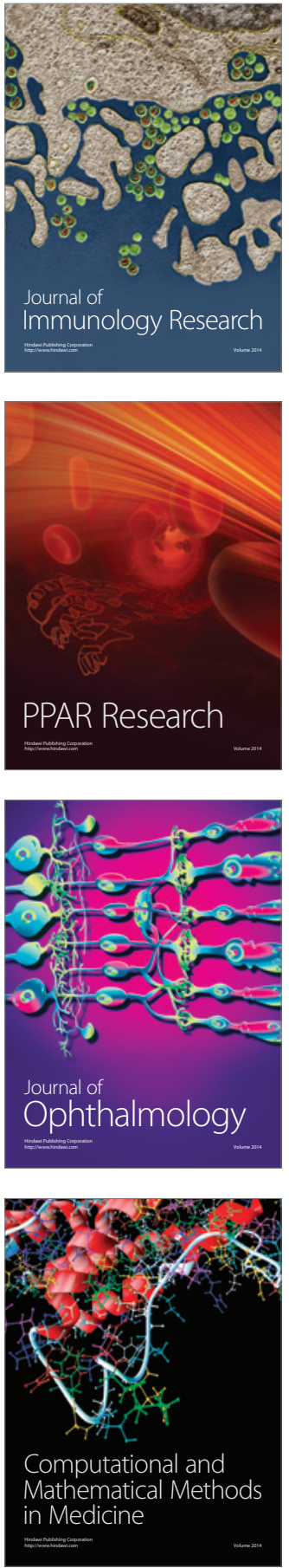

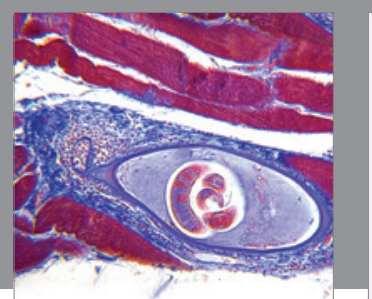

Gastroenterology Research and Practice

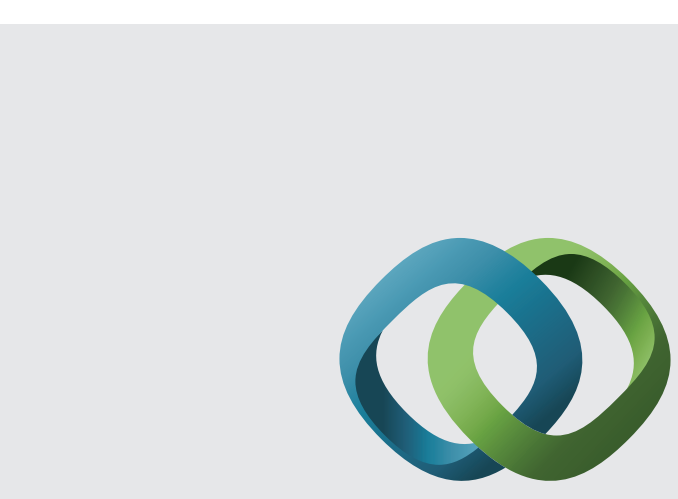

\section{Hindawi}

Submit your manuscripts at

http://www.hindawi.com
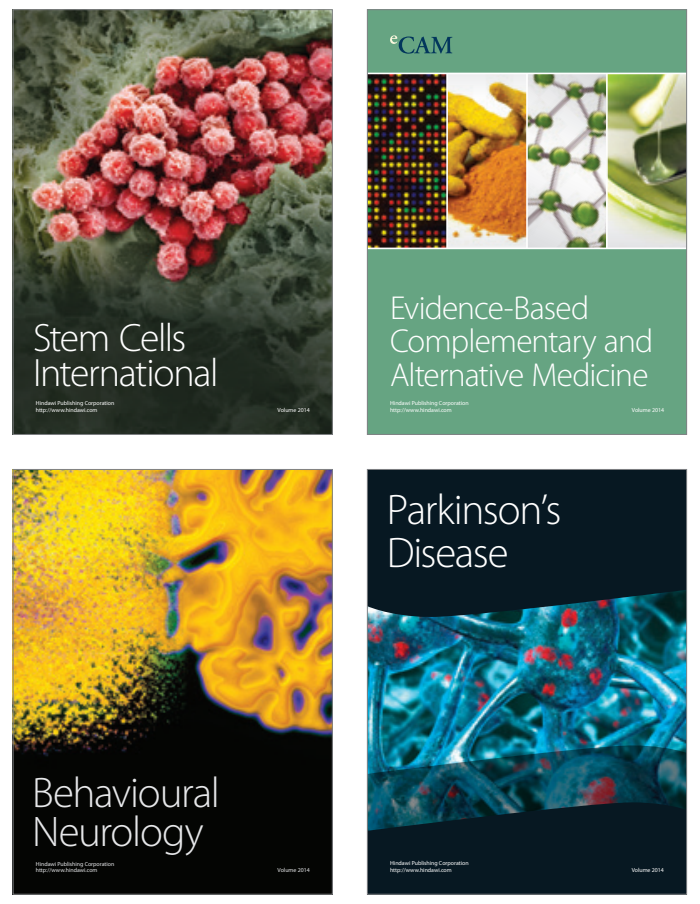
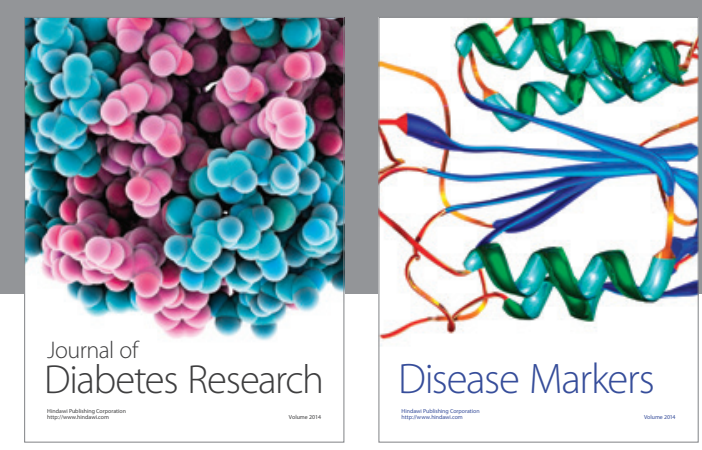

Disease Markers
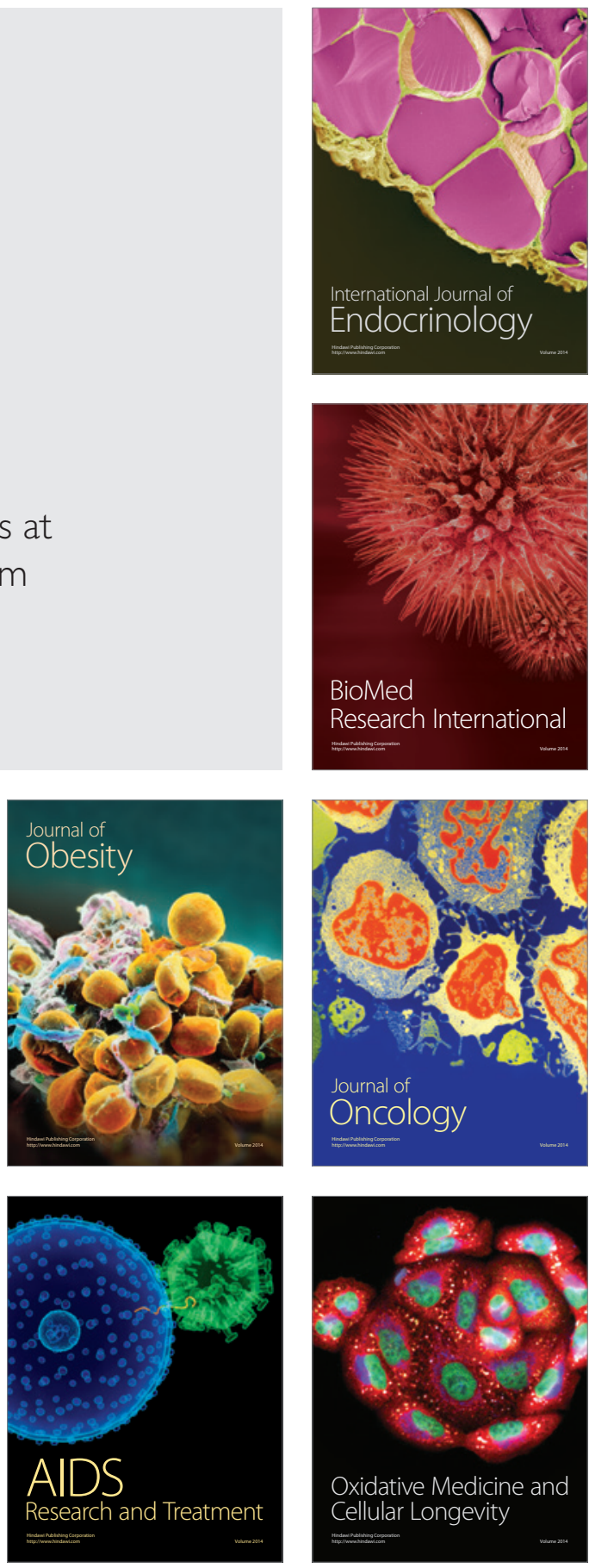